\title{
Transition from Childhood Nocturnal Enuresis to Adult Nocturia: A Systematic Review and Meta-Analysis
}

\author{
Susan Gong' \\ Lakshay Khosla (D) \\ Fred Gong' \\ Nikhil Kasarla' \\ Karel Everaert ${ }^{2}$ \\ Jeffrey Weiss' \\ Abdo Kabarriti ${ }^{1}$
}

'Department of Urology, State University of New York Downstate Health Sciences University, Brooklyn, NY, USA;

${ }^{2}$ Department of Uro-Gynecology, Ghent University Hospital, Ghent, Belgium
Correspondence: Susan Gong

Department of Urology, State University of New York Downstate Health Sciences University, 450 Clarkson Ave., Brooklyn,

NY, I I 203, USA

Tel + | 845-89|-6642

Email Susan.Gong@downstate.edu
Purpose: Current literature has suggested a relationship between nocturnal enuresis (NE) in childhood and the development of nocturia later in life as both disorders have similar underlying etiologies, comorbidities, and treatments. The objective was to synthesize the available evidence on the association between childhood NE and later presentation of nocturia.

Methods: PubMed, CINAHL, Scopus, and Google Scholar were searched for peer-reviewed studies published between January 1980 and April 2021. Case-control and cohort studies that reported on childhood NE and current nocturia were included. The PRISMA protocol was followed (PROSPERO ID: CRD42021256255). A random-effects model was applied to calculate the pooled odds ratio (OR) and $95 \%$ confidence interval (CI). Risk of bias was assessed using the Grading of Recommendations, Assessment, Development, and Evaluation (GRADE) criteria and with a funnel plot.

Results: Of the 278 articles identified, 8 studies met inclusion criteria. The 6 case-control and 2 prospective cohort studies resulted in a total sample size of 26,070 participants. In a random-effect pooled analysis, childhood NE was significantly associated with the development of nocturia (OR: 1.75, 95\% CI: 1.11-2.40). Significant heterogeneity $\left(\mathrm{I}^{2}=92.7 \%\right.$, $\mathrm{p}<0.01)$ was identified among the included studies, which was reflected in an asymmetrical funnel plot. NE and nocturia have similar underlying etiologies of hormonal abnormalities, sleep disorders, physiological disorders, and psychological disorders.

Conclusion: The history of childhood NE is significantly associated with nocturia later in life. The data in this meta-analysis support this transition and identify potential similarities between the two disorders. The sparse number of articles relevant to this topic is a strong indicator of the need for more work on this transition from childhood to maturity. More studies are warranted to further explore the association between NE and nocturia.

Keywords: LUTS, pediatric urology, incontinence, nocturnal polyuria

\section{Introduction}

Nocturnal enuresis (NE) is a bothersome incontinence condition usually present in childhood and defined as the involuntary passage of urine during sleep in children over 5 years of age. ${ }^{1}$ This disease affects $10 \%$ of 7 -year-olds but drops to a rate of $0.5 \%$ of adults. ${ }^{2}$ There is a misconception that NE is a benign disorder and resolves spontaneously; however, Yeung et al documented that in children with severe enuresis, the spontaneous resolution rate is only $50-60 \%{ }^{3}$ In addition to subclinical effects on self-esteem, quality of life and distress, NE is also linked with an increased rate of comorbid clinical behavioral disorders. ${ }^{4}$ Sleep arousal disorders, 
nocturnal polyuria, and decreased nocturnal bladder capacity all play a role in the pathogenesis of NE. ${ }^{2}$ Many of these underlying pathophysiological mechanisms are common to both NE and nocturia. Due to these similarities, there has been a suggestion that patients with childhood NE may go on to develop nocturia in adulthood. ${ }^{5}$

Nocturia is a common but often neglected symptom of adulthood, defined as waking at night one or more times to void. ${ }^{6}$ Nocturia is present in over $15 \%$ of men and women between the ages of 20 and $40 .{ }^{7}$ Nocturia is associated with elderly patients and increases with age up to a $50 \%$ prevalence in individuals older than $50 .^{7}$ It may reduce quality of life, productivity, and even cause physiological harm. ${ }^{7}$ Nocturnal polyuria, decreased nocturnal or global bladder capacity, and global polyuria have been proposed to be the main etiologies of nocturia. ${ }^{7}$

The main dissimilarity between NE and nocturia is the presence of appropriate arousal resulting from bladder stimulation to cause awakening in nocturia. ${ }^{8}$ Although differences exist in the expression of NE and nocturia, there are many similarities in the etiologies, comorbidities, and treatment. ${ }^{9} \mathrm{NE}$ and nocturia both have the underlying pathophysiological mechanism of nocturnal polyuria and decreased nocturnal bladder capacity. These overlaps and similarities in prevalence rates suggest a relationship between NE of childhood and nocturia of adulthood. Additionally, previous studies have shown that children with NE are more likely to experience nocturia and lower urinary tract symptoms in adulthood. ${ }^{10}$ Unfortunately, data are lacking on how and why NE transitions to nocturia; a better understanding of the pathophysiology of NE and nocturia can be important for a targeted therapeutic approach.

The goal of this paper is to conduct a systematic review and meta-analysis of studies investigating the relationship of NE of childhood to nocturia later in life. This paper will also summarize common pathophysiologies in order to suggest treatment options and identify future areas of research.

\section{Methods}

The meta-analysis of studies showing the transition from NE to nocturia was conducted according to the Preferred Reporting Items for Systematic Reviews and MetaAnalyses (PRISMA) extension statement for network meta-analysis. $^{11-14}$ The protocol was registered on PROSPERO (ID: CRD42021256255).

\section{Search Strategy}

In April 2021, two authors (SG and LK) designed and executed literature searches in PubMed, CINAHL, Scopus, and Google Scholar for studies published from January 1980 to April 2021 on studies connecting childhood NE to later nocturia. The year restriction was to allow for the greatest inclusion while ensuring the relevance of the studies. The search string included keywords such as "adult nocturia", "nocturnal polyuria", and additional terms to describe nocturia in adults and "childhood enuresis", "childhood bedwetting", and other terms describing childhood NE. Initial screening was performed independently by two investigators (SG and LK) based on the titles and abstracts of the article. Reasons for exclusions were noted, and potentially relevant studies were subjected to a full-text review. Data extraction confirmed the relevance of the reports. Disagreements were resolved via consensus with the co-authors.

\section{Inclusion and Exclusion Criteria}

Two authors (SG and LK) independently screened articles for studies that met the inclusion criteria. Studies were included if they followed children with $\mathrm{NE}$ to see if nocturia occurred later in life (prospective cohort study) or if they tracked the history of NE in nocturia patients (case-control study). We focused on primary monosymptomatic NE, which is characterized by enuresis during sleep in children who have never achieved a satisfactory period of nighttime dryness and who lack symptoms of the lower urinary tract and/or daytime incontinence. ${ }^{15-17} \mathrm{We}$ used the definition of one or more voids per night for nocturia. ${ }^{18}$ We excluded studies which had comorbidities (eg spina bifida occulta), ${ }^{19}$ only focused on animal cases, or did not discuss both childhood NE and nocturia in the title and abstract sorting. In full-text screening, we excluded studies which were narrative reviews or had insufficient data. Included studies must have NE occurring in childhood and nocturia occurring later in life.

\section{Data Extraction}

Two authors (SG and LK) created a data extraction sheet to record the following information: the first author's surname, publication year, number and age of participants, study design (cohort or case control) and duration, the country where the study was performed, and outcomes measured. Subsequently, the odds ratios (OR) and $95 \%$ confidence intervals (CI) of the association of $\mathrm{NE}$ and 
nocturia were retrieved. All discrepancies regarding data extraction were resolved by consensus with the committee of authors.

\section{Risk of Bias Assessment}

Two authors (FG and LK) independently assessed the quality of the included studies using GRADE (Grading of Recommendations, Assessment, Development and Evaluations) criteria and the level of evidence was rated according to the criteria provided by the Oxford Centre for Evidence-Based Medicine (OCEBM). ${ }^{20,21}$ Disagreements were resolved by consultation with the coauthors.

\section{Statistical Analyses}

Odds ratios (OR) and 95\% confidence intervals (CI) were utilized to pool data from the existing literature of casecontrol and cohort studies. The standard error of each study was then calculated from the existing data. Statistical significance for all analyses was set at $\mathrm{p}<$ 0.05 (two-tailed). Heterogeneity was assessed via the Cochran $\mathrm{Q}$ and the $\mathrm{I}^{2}$ statistics. Significant heterogeneity was identified in a fixed effect model, prompting the use of the random effects model to calculate the cumulative effect size and CI. Potential publication bias was evaluated using a funnel plot. All analysis was performed using the $\mathrm{R}$ software (version 3.4.0) and the R packages metafor and ggplot2.

\section{Results}

\section{Study Selection and Characteristics}

Our initial search identified 278 publications, and after the elimination of duplicates, 259 publications were available. After sorting through titles and abstracts, 19 studies were selected for full-text review. Based on selection criteria, 8

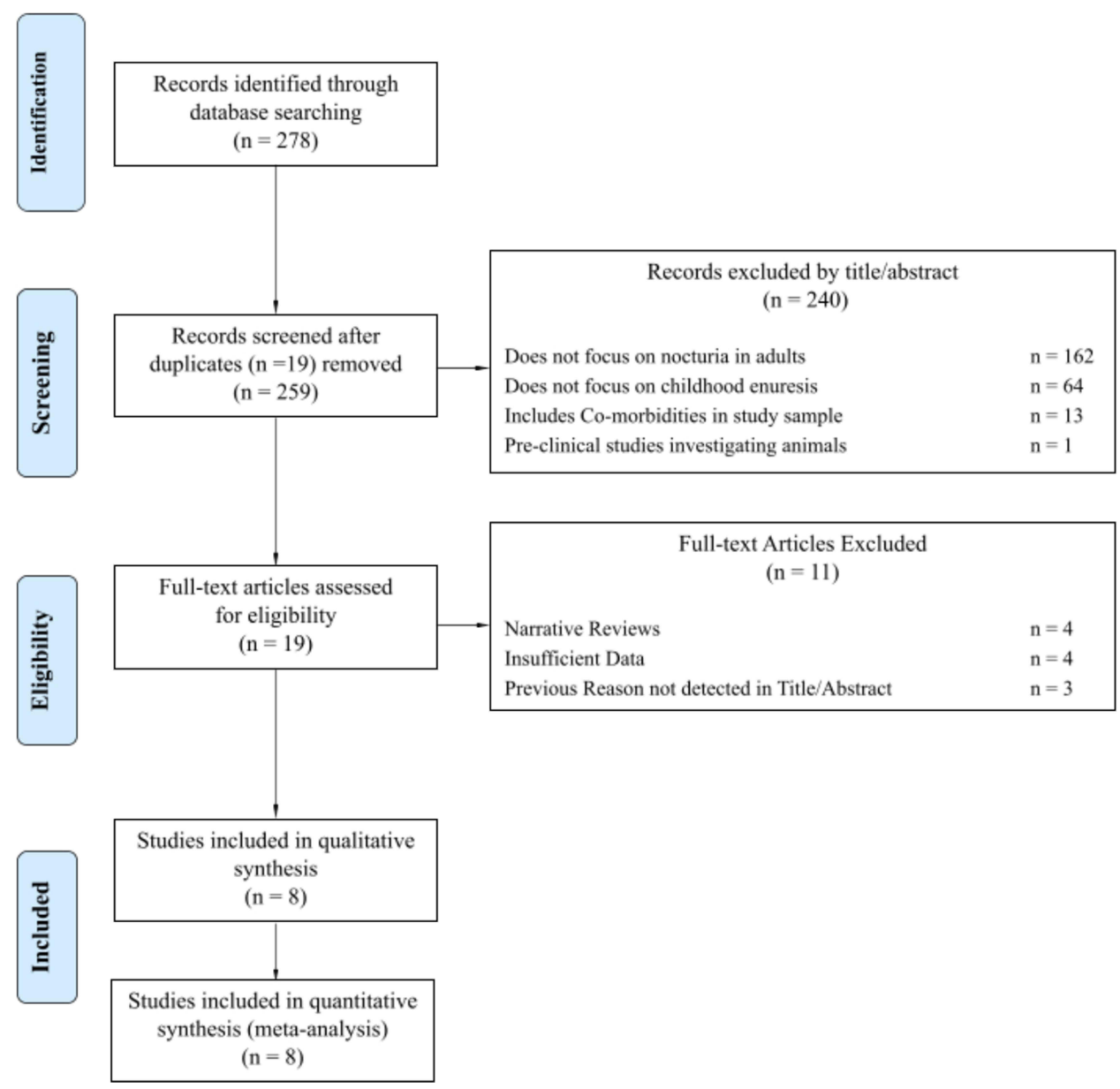

Figure I Study selection flow diagram. Flow diagram of articles screened showing the study selection process using PRISMA (Preferred Reporting Items for Systematic Reviews and Meta-Analyses). Screening was done using inclusion and exclusion criteria. All screened studies were published between January 1980 and April 2021.

Notes: PRISMA figure adapted from Moher D, Liberati A, Altman D, Tetzlaff J, et al. The PRISMA statement for reporting systematic reviews and meta-analyses of studies that evaluate health care interventions: explanation and elaboration. Journal of clinical epidemiology. 2009;62(I0). Creative Commons. ${ }^{12}$ 
studies were identified, comprising 26,070 patients for the meta-analysis. The detailed retrieval process is shown in Figure 1. These studies, published between 2010 and 2021, were case-control or prospective cohort studies that connected the current history of nocturia to the childhood history of NE. Summaries of study design and outcomes measured from these eight studies are shown in Table 1 . The ratio of male/female varied between studies, with a total of 3692 male subjects and 22,378 female subjects. These studies were performed in six different countries (Turkey, Japan, USA, Colombia, England, Sweden). The earliest study began in 1991, while the most recent study was conducted in 2014. The case-control studies (studies 1-3, 6-8) asked adults about nocturia symptoms and to recall childhood NE. ${ }^{22-27}$ The prospective cohort studies (studies 5 and 6) followed children with

Table I Study Characteristics

\begin{tabular}{|c|c|c|c|c|c|c|c|}
\hline Study & $\begin{array}{l}\text { First Author } \\
\text { Last Name, } \\
\text { Year }\end{array}$ & $\begin{array}{l}\mathbf{N}(\% \\
\mathbf{M} / \% \\
\text { F) }\end{array}$ & $\begin{array}{l}\text { Age } \\
\text { (Years) }\end{array}$ & $\begin{array}{l}\text { Study } \\
\text { Design }\end{array}$ & Country & $\begin{array}{l}\text { Study } \\
\text { Duration }\end{array}$ & Outcomes Measured \\
\hline 1 & Akashi, 2014 & $\begin{array}{l}2555 \\
(44 \% / \\
56 \%)\end{array}$ & $30-89$ & $\begin{array}{l}\text { Case } \\
\text { control }\end{array}$ & Japan & July-August 2012 & $\begin{array}{l}\text {-Childhood history of urinary symptoms } \\
\text {-Age of NE resolution } \\
\text {-Current urinary symptoms } \\
\text {-Nocturia, urgency }\end{array}$ \\
\hline 2 & Azuero, 202I & $\begin{array}{l}1060 \\
(50 \% / \\
50 \%)\end{array}$ & $18-89$ & $\begin{array}{l}\text { Case } \\
\text { control }\end{array}$ & Colombia & 2015 & $\begin{array}{l}\text {-Sociodemographic characteristics } \\
\text {-Race, education, socioeconomic status, marital } \\
\text { status, employment status, } \\
\text {-Childhood history of urinary symptoms } \\
\text {-Age of NE resolution, bedwetting } \\
\text {-Current urinary symptoms } \\
\text {-Nocturia, voids per night, symptom bother }\end{array}$ \\
\hline 3 & $\begin{array}{l}\text { Fitzgerald, } \\
2006\end{array}$ & $\begin{array}{l}2109 \\
(0 \% / \\
100 \%)\end{array}$ & $40-69$ & $\begin{array}{l}\text { Case } \\
\text { control }\end{array}$ & USA & 2004 & $\begin{array}{l}\text {-Sociodemographic characteristics } \\
\text {-Race, marital status, education, total household } \\
\text { income, occupation } \\
\text {-Childhood history of urinary symptoms } \\
\text {-NE, frequent daytime voids, nocturia, daytime } \\
\text { urinary incontinence, nocturnal enuresis, } \\
\text { frequency of UTI } \\
\text {-Current urinary symptoms } \\
\text {-Nocturia, daytime void frequency, urgency, } \\
\text { incontinence, UTI }\end{array}$ \\
\hline 4 & Heron, 2017 & $\begin{array}{l}920 \\
(51 \% / \\
49 \%)\end{array}$ & $4-14$ & $\begin{array}{l}\text { Prospective } \\
\text { cohort }\end{array}$ & England & $199 \mid-2005$ & $\begin{array}{l}\text {-Sociodemographic characteristics } \\
\text {-Social class, home ownership, car access, } \\
\text { maternal education } \\
\text {-Childhood urinary symptoms } \\
\text {-NE, bedwetting frequency, daytime void frequency } \\
\text {-Current urinary symptoms } \\
\text {-Nocturia, daytime wetting, bedwetting, urgency, } \\
\text { frequent urination, low void volume, void } \\
\text { postponement }\end{array}$ \\
\hline 5 & Negoro, 2020 & $\begin{array}{l}5402 \\
(29 \% / \\
71 \%)\end{array}$ & $30-75$ & $\begin{array}{l}\text { Prospective } \\
\text { cohort }\end{array}$ & Japan & $2008-2010$ & $\begin{array}{l}\text {-Childhood urinary symptoms } \\
\text {-NE } \\
\text {-Current urinary symptoms } \\
\text {-Nocturia, lower urinary tract symptoms, } \\
\text { urgency, incontinence }\end{array}$ \\
\hline
\end{tabular}

(Continued) 
Table I (Continued).

\begin{tabular}{|l|l|l|l|l|l|l|l|}
\hline Study & $\begin{array}{l}\text { First Author } \\
\text { Last Name, } \\
\text { Year }\end{array}$ & $\begin{array}{l}\text { N (\% } \\
\text { M/\% } \\
\text { F) }\end{array}$ & $\begin{array}{l}\text { Age } \\
\text { (Years) }\end{array}$ & $\begin{array}{l}\text { Study } \\
\text { Design }\end{array}$ & Country & $\begin{array}{l}\text { Study } \\
\text { Duration }\end{array}$ & Outcomes Measured \\
\hline 6 & Othman, 202I & $\begin{array}{l}9197 \\
(0 \% / \\
100 \%)\end{array}$ & $25-64$ & $\begin{array}{l}\text { Case } \\
\text { control }\end{array}$ & Sweden & 2014 & $\begin{array}{l}\text {-Childhood urinary symptoms } \\
\text {-Age of NE resolution } \\
\text {-Current urinary symptoms } \\
\text {-Nocturia, incontinence, urgency, overactive } \\
\text { bladder, pelvic floor disorder, pelvic organ } \\
\text { prolapse }\end{array}$ \\
\hline 7 & Sarici, 2014 & $\begin{array}{l}4250 \\
(0 \% / \\
100 \%)\end{array}$ & $15-49$ & $\begin{array}{l}\text { Case } \\
\text { control }\end{array}$ & Turkey & January-May \\
2013 & $\begin{array}{l}\text {-Childhood history of urinary symptoms } \\
\text {-NE } \\
\text {-Current urinary symptoms } \\
\text {-Nocturia, urge incontinence, frequency, urgency, } \\
\text { overactive bladder }\end{array}$ \\
\hline 8 & Yazici, 2013 & $\begin{array}{l}577 \\
(0 \% / \\
100 \%)\end{array}$ & $17-24$ & $\begin{array}{l}\text { Case } \\
\text { control }\end{array}$ & Turkey & $\begin{array}{l}\text { November 20II- } \\
\text { April 20I2 }\end{array}$ & $\begin{array}{l}\text {-Childhood history of urinary symptoms } \\
\text {-NE } \\
\text {-Current urinary symptoms } \\
\text {-Nocturia and frequency }\end{array}$ \\
\hline
\end{tabular}

Abbreviation: NE, nocturnal enuresis.

NE into adulthood. ${ }^{28,29}$ All studies measured childhood history of urinary symptoms (eg NE, daytime voids) and current urinary symptoms (eg nocturia, UTI, incontinence). Only studies 2, 3, and 4 provided detailed sociodemographic data (eg race, education, marital status). ${ }^{23,24,29}$

\section{Network Meta-Analysis}

Bivariate ORs with their corresponding 95\% CIs for each individual study and for the combination of all included studies are presented in Figure 2. Overall, the pooled estimate of the OR was 1.75 (95\% CI: 1.11-2.40) based on eight studies in a random effects model with significant heterogeneity $\left(I^{2}=92.7 \%, p<0.01\right)$. So, childhood NE was significantly associated with the incidence of nocturia.

\begin{tabular}{|c|c|c|c|c|}
\hline Study & $\mathrm{n}$ & & & Estimate $[95 \% \mathrm{Cl}]$ \\
\hline Akashi_2014 & 2555 & $\longmapsto$ & & $2.38[1.94,2.94]$ \\
\hline Azuero_2021 & 1060 & $\longmapsto$ & & $1.45[0.99,2.13]$ \\
\hline Fitzgerald_2006 & 2109 & & & $0.67[0.41,1.10]$ \\
\hline Heron_2017 & 920 & -1 & & $1.23[0.95,1.58]$ \\
\hline Negoro_2020 & 5402 & $=$ & & $1.39[1.20,1.57]$ \\
\hline Othman_2021 & 9197 & $\mapsto$ & & $1.91[1.53,2.38]$ \\
\hline Sarici_2014 & 4250 & & & $3.75[2.55,5.52]$ \\
\hline Yazici_2014 & 577 & & & $1.08[0.49,2.39]$ \\
\hline \multirow{4}{*}{$\begin{array}{l}\text { RE Model } \\
Q=57.97, d f=7, p=0\end{array}$} & $0.00 ; I^{2}=92.7 \%$ & - & & $1.75[1.11,2.40]$ \\
\hline & 00 & $i \quad 1$ & 1 & \\
\hline & $\begin{array}{ll}-1 & 0\end{array}$ & 12 & 4 & \\
\hline & & Odds Ratio & & \\
\hline
\end{tabular}

Figure 2 Individual and pooled OR of included studies.

\section{Quality Assessment and Publication Bias}

Based on the GRADE criteria, which factors in an evaluation of publication bias, a quality of evidence rating of low (study 4), ${ }^{29}$ moderate (studies 1-3, 6$8),{ }^{22-27}$ or high (study 5$)^{28}$ was given (Table 2). With the OCEBM criteria, six studies (1-3 and 6-8 $)^{22-27}$ were level $3 \mathrm{~b}$ while two studies $(4-5)^{28,29}$ were level 1b. A funnel plot was used to evaluate publication bias (Figure 3). Upon visual inspection of the plot, a certain degree of asymmetry was observed.

\section{Discussion}

To the best of our knowledge, this paper is the first metaanalysis assessing the association between childhood NE and adult nocturia. A total of 26,070 participants in casecontrol and prospective cohort studies were included in our meta-analysis. Our results showed that there was a significant association between the history of NE and the development or persistence of nocturia later in life.

For the included studies, sample sizes ranged from 577 participants to 9197 participants and studies were either case control or prospective cohort. Most ORs of the individual studies ranged between 1.00 and $2.00 .^{23,25,27-29}$ Specifically, studies $1,5,6$, and 7 showed statistically significant associations between the two conditions (OR: 2.38, CI: 1.94-2.94; OR: 1.39, CI: 1.20-1.57; OR: 1.91, CI: 
Table 2 Assessment of Study Quality Using GRADE Quality Assessment Criteria

\begin{tabular}{|l|c|l|l|l|l|l|l|}
\hline Study & Author, Year & Risk of Bias & Inconsistency & Indirectness & Imprecision & Publication Bias & Quality Rating \\
\hline $\mathbf{I}$ & Akashi, 2014 & Not serious & Not serious & Serious & Not serious & None & Moderate \\
2 & Azuero, 202I & Not serious & Not serious & Not serious & Serious & None & Moderate \\
3 & Fitzgerald, 2006 & Not serious & Not serious & Serious & Not serious & None & Moderate \\
4 & Heron, 2017 & Serious & Not serious & Serious & Not serious & None & Low \\
5 & Negoro, 2020 & Not serious & Not serious & Not serious & Not serious & None & High \\
6 & Othman, 202I & Not serious & Not serious & Serious & Not serious & None & Moderate \\
7 & Sarici, 2014 & Not serious & Not serious & Serious & Not serious & None & Moderate \\
8 & Yazici, 2013 & Not serious & Not serious & Serious & Not serious & None & Moderate \\
\hline
\end{tabular}

1.53-2.38; OR: 3.75, CI: 2.55-5.52; respectively)..$^{22,25,26,28}$ Overall, the pooled random effects model also showed a significant association between $\mathrm{NE}$ and nocturia (OR: 1.75, CI: 1.11-2.40). A pooled random effects model was used in order to take into account both within- and betweenstudy variability when calculating pooled OR estimates. This suggests that a history of childhood enuresis is associated with an increased risk of occurrence of nocturia later in life. The heterogeneity was statistically significant, $\mathrm{I}^{2}=$ $92.7 \%$, which indicates differences between study results beyond those attributable to chance. This could be due to methodological variation in study design as case control and prospective cohort studies were included. Furthermore, clinical differences between studies, such as varied populations, would also increase heterogeneity. For example, although we wished to include only primary monosymptomatic NE, some studies did not specify their classification of NE. Additionally, the definition of primary monosymptomatic NE has been amended throughout the years. Thus, data on secondary or non-monosymptomatic NE may have been included. Also, studies 3, 5, 6, 7, and 8 were predominantly

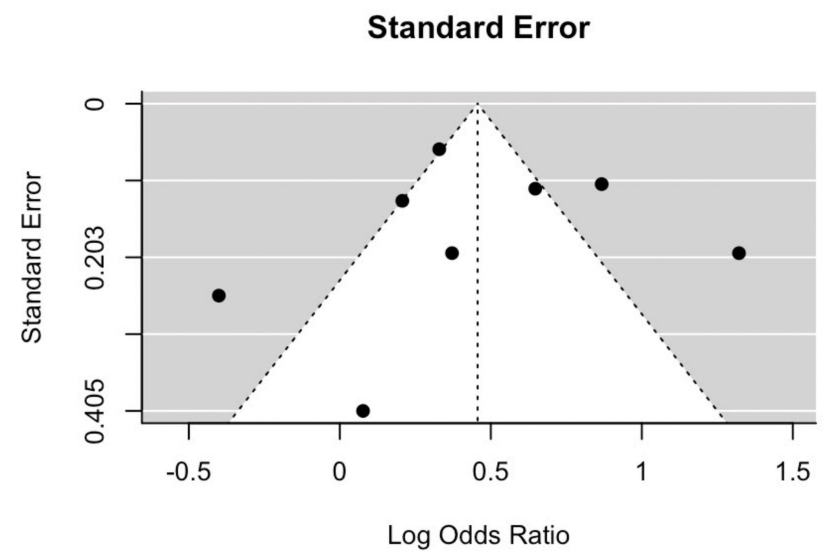

Figure 3 Funnel plot. female, while studies 1, 2, and 4 had more equal sex distribution. The heterogeneity of the studies could have contributed to an asymmetrical funnel plot. In addition to heterogeneity, reporting bias and chance can cause asymmetry. $^{30}$

Previous studies have noted the similarities between NE and nocturia. A genetic factor is suspected for both conditions. $^{31}$ Chromosomes $12 \mathrm{q}, 13 \mathrm{q}$, and $22 \mathrm{q}$ have loci associated with NE phenotypes, and these potential NE risk genes have been identified with roles in sleep, urine production, and bladder function. ${ }^{31,32}$ Nocturia has a strong familial occurrence and differs in prevalence by ethnicity. ${ }^{31}$ Furthermore, physical and mental health are compromised in both conditions. While children with NE have comorbidities of constipation, attention deficit disorder, and low selfesteem, adults with nocturia have comorbidities of cardiovascular disease, fall injuries, personal distress, and depression. ${ }^{31}$ For both conditions, a more individualized approach seems to be necessary; however, treatment is often inadequate. Due to the persisting mindset that $\mathrm{NE}$ and nocturia are "normal", treatment options have not been pursued adequately by patients and doctors. Although there are many similarities between NE and nocturia, one major difference is the arousal owing to bladder stimuli. ${ }^{31}$ This suggests that the bladder-brain dialogue during sleep and sleep characteristics play a key role in these conditions.

The similarities between NE and nocturia may provide an explanation for the mechanism of transition from $\mathrm{NE}$ to nocturia. Both disorders are direct consequences of a disparity between bladder capacity and nocturnal urine production. ${ }^{33,34}$ Factors associated with the pathophysiologies of NE and nocturia include hormonal abnormalities, sleep disorders, physiological disorders, and psychological disorders. Normally, nocturnal urine production is $<20 \%$ of the daily urine output in young adults and $<30 \%$ of the daily urine output among older adults. ${ }^{35}$ The amount and 
frequency of nocturnal urination is related to fluid intake before going to bed, as well as to endocrine factors. Studies have shown that low levels of nocturnal argininevasopressin may result in overproduction of urine at night, nocturnal polyuria. ${ }^{36,37}$ Nocturnal polyuria may result in $\mathrm{NE}$ and nocturia. Children with NE and nocturia exhibit little circadian variation in urine excretion rate, urine osmolality, or vasopressin secretion, and produce large volumes of dilute urine during the night. If this abnormal hormonal circadian rhythm is not corrected, NE can persist or transition into nocturia in adulthood.

NE and nocturia are also linked to sleep disorders. ${ }^{31}$ An abnormally deep sleep pattern may occur in children with enuresis. $^{38}$ Additionally, obstructive sleep apnea (OSA) has been cited as a precipitating condition associated with NE. ${ }^{34}$ Similarly, findings suggest that men with OSA have a high incidence of nocturia. ${ }^{35}$ Thus, untreated OSA in children may present as nocturia in adulthood.

Additionally, NE and nocturia can be connected through physiological disorders, such as lower bladder capacity and detrusor overactivity. Children with NE have diminished functional bladder capacity and detrusor instability, which may be due to delayed maturation of the bladder and its functional controlling signal pathways. ${ }^{2,39}$ It is also known that the bladder contributes to nocturia in the case of low capacity, urgency, and detrusor overactivity. ${ }^{37,40}$ An inability to hold urine at night and uninhibited bladder contractions may result from issues in bladder development, which begin in childhood and carry on into adulthood, resulting in NE, then nocturia.

Furthermore, there has been evidence of a relationship between psychological disorders and the onset of NE and nocturia. Psychological stress is a precipitating condition associated with enuresis. ${ }^{34} \mathrm{NE}$ is considered a regressive symptom in response to stress (eg parental divorce, sexual abuse, trauma). ${ }^{34}$ Comparably, nocturia is positively associated with childhood and adolescent/adult sexual, physical, and emotional abuse. $^{41}$ If these underlying psychological traumas are not addressed in a child, it is possible that these conditions will persist into adulthood and present as nocturia.

$\mathrm{NE}$ in children and nocturia in adults have similar underlying mechanisms, which support the transition of NE into nocturia with increasing age. Aging is known to impact the lower urinary tract (LUT) through a variety of mechanisms. In addition to muscle and nerve damage due to ischemia, vascular damage due to endothelial dysfunction and inflammation is commonly associated with LUT disorders, which may be present with the phenotype complaint of nocturia. $^{42-45}$ The mechanisms by which these damaging factors manifest due to aging are being studied at the molecular level. Age-related changes in the levels of hormones, receptors, and increases in reactive oxygen species may increase oxidative stress and cause the transition from NE to nocturia. ${ }^{46-49}$ Children with NE have higher prevalences of a variety of bladder symptoms, such as bedwetting, urgency, and frequent urination; accordingly, patients with NE may be more prone to these aging mechanisms in the urinary tract. ${ }^{29}$ More studies are needed to elucidate the mechanisms by which NE progresses to nocturia. The use of a 24-hour bladder diary, nocturnal bladder diary, renal functional profiles and other tools in a controlled setting may assist in providing more information in understanding the $\mathrm{NE}$ to nocturia transition.

\section{Consideration and Limitations}

Long-term follow-up studies in children with NE are lacking, which has led to the misconception that once incontinence is resolved in childhood, the patient is cured. However, our meta-analysis provides strong evidence that NE in childhood is associated with the development or persistence of nocturia later. Most people with nocturia do not seek help, accepting it as a natural consequence of aging; however, nocturia is common in men and women of all ages, profoundly lowers the quality of life, and may be associated with increased morbidity and mortality. ${ }^{50}$ The understanding that there is a connection between childhood NE and adult nocturia can provide treatment options that may thwart the occurrence of nocturia. Currently, both are treated through lifestyle changes, drugs (eg desmopressin), and behavioral therapy. ${ }^{7}$ Verbal behavioral therapy, in combination with a written checklist of behavioral instructions or desmopressin, has been shown to increase rates of treatment compliance in children with NE. ${ }^{51}$ Treatment of childhood NE may be equally effective in preventing later development of nocturia if the underlying cause is the same. Future studies should consider the mechanisms of NE transitioning to nocturia.

The findings of our review have several limitations. To begin with, heterogeneity was observed across studies $\left(\mathrm{I}^{2}\right.$ $=92.7 \%, \mathrm{p}<0.01)$ and the funnel plot was asymmetrical. The high heterogeneity underscores the need for further research into this topic given the limited number of studies with high-quality evidence. As a future consideration, we 
can perform meta-regressions to better understand what is behind the high heterogeneity. Additionally, four databases were used, so despite conducting comprehensive searches, articles that were not indexed in the used databases were missing. Also, only studies 2, 3 and 4 provided detailed demographic data (eg race, education, marital status). 9,10,12 Most studies lack this information, which makes it difficult to account for these factors as possible confounders. Furthermore, most studies were case-control studies, which had the risk of recall bias since adults were asked to remember if they had NE as a child. ${ }^{22}$ Even though their responses are confirmed by caregiver responses whenever possible, this design runs the risk of inaccurate retrieval of past information.

Despite these limitations, our review is the first to conduct a meta-analysis on the transition from childhood NE to later nocturia. Our study had several important strengths. First, we tested several search constructions and selected the ones that allowed for the broadest selection of articles. Second, we searched four databases and had two reviewers independently screen studies to reduce selection bias. Third, we used two quality assessment methods, GRADE and OCEBM criteria. Finally, various stratified and publication bias analyses were performed to comprehensively evaluate the robustness of the combined effect size estimate.

Numerous studies, including this meta-analysis, have indicated an association between NE and nocturia. However, further studies are needed to explore the transition from NE to nocturia in the context of pathophysiologies, prognosis, and treatment outcomes.

\section{Conclusion}

In summary, this meta-analysis of case-control and prospective cohort studies found an association between the history of NE and the occurrence of nocturia later in life. $\mathrm{NE}$ and nocturia have similar underlying conditions, links to genetic factors, and resulting physical and mental health issues. Thus, findings in NE in children may be useful in elucidating the missing links in knowledge about nocturia in adults. The sparse number of articles relevant to this topic is a strong indicator of the need for more work on the transition from childhood to maturity. Data gathered herein provide targets for future studies, and highlight the necessity for further investigation regarding prognosis and treatment outcomes.

\section{Disclosure}

Professor Karel Everaert reports grants from Ferring, during the conduct of the study; grants from Medtronic, outside the submitted work; and Minority share holder without salary from P2Solutions (smart textile applications). Dr Jeffrey Weiss received honoraria as a consultant from Ferring and Evidera, also an uncompensated consultant from IBPR, outside the submitted work. The authors report no other conflicts of interest in this work.

\section{References}

1. Hashim H, Blanker MH, Drake MJ, et al. International continence society (ICS) report on the terminology for nocturia and nocturnal lower urinary tract function. Neurourol Urodyn. 2019;38(2):499-508. doi:10.1002/nau. 23917

2. Nevéus T. Diagnosis and management of nocturnal enuresis. Curr Opin Pediatr. 2009;21(2):199-202. doi:10.1097/MOP.0b013e328 3229b12

3. Yeung CK, Sreedhar B, Sihoe JDY, Sit FKY, Lau J. Differences in characteristics of nocturnal enuresis between children and adolescents: a critical appraisal from a large epidemiological study. $B J U$ Int. 2006;97(5):1069-1073. doi:10.1111/j.1464-410X.2006.06074.x

4. von Gontard A, Baeyens D, Van Hoecke E, Warzak WJ, Bachmann C. Psychological and psychiatric issues in urinary and fecal incontinence. J Urol. 2011;185(4):1432-1436. doi:10.1016/j. juro.2010.11.051

5. Mangani S, Sauro F, Ponticelli A. Nocturia in mothers and enuresis in children: possible links. Turk $J$ Urol. 2019;46(2):146-151. doi:10.5152/tud.2019.19147

6. Abrams P, Cardozo L, Fall M, et al. The standardisation of terminology in lower urinary tract function: report from the standardisation sub-committee of the international continence society. Urology. 2003;61(1):37-49. doi:10.1016/S0090-4295(02)02243-4

7. Weiss JP, Blaivas JG, Bliwise DL, et al. The evaluation and treatment of nocturia: a consensus statement. BJU Int. 2011;108(1):6-21. doi:10.1111/j.1464-410X.2011.10175.x

8. Wolfish NM, Pivik RT, Busby KA. Elevated sleep arousal thresholds in enuretic boys: clinical implications. Acta Paediatr. 1997;86 (4):381-384. doi:10.1111/j.1651-2227.1997.tb09027.x

9. Djurhuus JC, Matthiesen TB, Rittig S. Similarities and dissimilarities between nocturnal enuresis in childhood and nocturia in adults. $B J U$ Int. 1999;84(Suppl 1):9-12. doi:10.1046/j.1464-410x.84.s1.1.x

10. Goessaert AS, Schoenaers B, Opdenakker O, Hoebeke P, Everaert K, Vande Walle J. Long-term followup of children with nocturnal enuresis: increased frequency of nocturia in adulthood. $J$ Urol. 2014;191 (6):1866-1870. doi:10.1016/j.juro.2013.12.051

11. Hutton B, Salanti G, Caldwell DM, et al. The PRISMA extension statement for reporting of systematic reviews incorporating network meta-analyses of health care interventions: checklist and explanations. Ann Intern Med. 2015;162(11):777-784. doi:10.7326/M14-2385

12. Moher D, Liberati A, Tetzlaff J, Altman DG; PRISMA Group. Preferred reporting items for systematic reviews and meta-analyses: the PRISMA statement. BMJ. 2009;339:b2535. doi:10.1136/bmj.b2535

13. Moher D, Shamseer L, Clarke M, et al. Preferred reporting items for systematic review and meta-analysis protocols (PRISMA-P) 2015 statement. Syst Rev. 2015;4(1):1. doi:10.1186/2046-4053-4-1

14. Page MJ, McKenzie JE, Bossuyt PM, et al. The PRISMA 2020 statement: an updated guideline for reporting systematic reviews. BMJ. 2021;372:n71. doi:10.1136/bmj.n71 
15. Austin PF, Bauer SB, Bower W, et al. The standardization of terminology of lower urinary tract function in children and adolescents: update report from the standardization committee of the international children's continence society. Neurourol Urodyn. 2016;35 (4):471-481. doi:10.1002/nau.22751

16. Nørgaard JP, van Gool JD, Hjälmås K, Djurhuus JC, Hellström AL. Standardization and definitions in lower urinary tract dysfunction in children. international children's continence society. $\mathrm{Br} J$ Urol. 1998;81(Suppl 3):1-16. doi:10.1046/j.1464-410x.1998.00025.x

17. Nevéus T, von Gontard A, Hoebeke P, et al. The standardization of terminology of lower urinary tract function in children and adolescents: report from the standardisation committee of the international children's continence society. $J$ Urol. 2006;176(1):314-324. doi:10.1016/S0022-5347(06)00305-3

18. Weiss JP. Nocturia: focus on etiology and consequences. Rev Urol. 2012;14(3-4):48-55

19. Yavuz A, Bayar G, Kilinc MF, Sariogullari U. The relationship between nocturnal enuresis and spina bifida occulta: a prospective controlled trial. Urology. 2018;120:216-221. doi:10.1016/j. urology.2018.07.038

20. Page MJ, McKenzie JE, Higgins JPT. Tools for assessing risk of reporting biases in studies and syntheses of studies: a systematic review. BMJ Open. 2018;8(3):e019703. doi:10.1136/bmjopen-2017019703

21. Durieux N, Vandenput S, Pasleau F. OCEBM levels of evidence system. Rev Med Liege. 2013;68(12):644-649.

22. Akashi S, Tomita K. The impact of a history of childhood nocturnal enuresis on adult nocturia and urgency. Acta Paediatr. 2014;103 (9):410. doi:10.1111/apa.12694

23. Azuero J, Santander J, Trujillo CG, et al. Potential associations of adult nocturia. results from a national prevalence study. Neurourol Urodyn. 2021;40:819-828. doi:10.1002/nau.24624

24. Fitzgerald MP, Thom DH, Wassel-Fyr C, et al. Childhood urinary symptoms predict adult overactive bladder symptoms. J Urol. 2006;175(3 Pt 1):989-993. doi:10.1016/S0022-5347(05)00416-7

25. Othman JA, Åkervall S, Molin M, Gyhagen M. Childhood nocturnal enuresis-a marker for pelvic floor disorders and urinary tract symptoms in women? Int Urogynecol J. 2021;32(2):359-365. doi:10.1007/ s00192-020-04345-x

26. Sarici H, Telli O, Özgür BC, Doluoğlu ÖG, Eroğlu M, Bozkurt S. A population-based study of factors associated with nocturia in reproductive-aged Turkish women. Korean J Urol. 2014;55 (6):405-410. doi:10.4111/kju.2014.55.6.405

27. Yazici CM, Abali R, Tasdemir N, Dogan C, Yildiz T. Is nocturia of young adulthood a remnant of childhood nocturnal enuresis? Int Urogynecol J. 2014;25(2):273-278. doi:10.1007/s00192-013-2203-y

28. Negoro H, Fukunaga A, Setoh K, et al. Medical history of nocturnal enuresis during school age is an independent risk factor for nocturia in adults: the nagahama study. Neurourol Urodyn. 2021;40 (1):326-333. doi:10.1002/nau.24562

29. Heron J, Grzeda MT, von Gontard A, Wright A, Joinson C. Trajectories of urinary incontinence in childhood and bladder and bowel symptoms in adolescence: prospective cohort study. BMJ Open. 2017;7(3):e014238. doi:10.1136/bmjopen-2016-014238

30. Sterne JA, Sutton AJ, Ioannidis JP, et al. Recommendations for examining and interpreting funnel plot asymmetry in meta-analyses of randomised controlled trials. BMJ. 2011;343:d4002. doi:10.1136/ bmj.d4002

31. Goessaert AS, Everaert K, Hoebeke P, Kapila A, Walle JV. Nocturnal enuresis and nocturia, differences and similarities - lessons to learn? Acta Clin Belg. 2015;70(2):81-86. doi:10.1179/2295333714Y.0000000055
32. Jørgensen CS, Horsdal HT, Rajagopal VM, et al. Identification of genetic loci associated with nocturnal enuresis: a genome-wide association study. Lancet Child Adolesc Health. 2021;5(3):201-209. doi:10.1016/S2352-4642(20)30350-3

33. Hjalmas K, Arnold T, Bower W, et al. Nocturnal enuresis: an international evidence based management strategy. J Urol. 2004;171(6 Pt 2):2545-2561. doi:10.1097/01.ju.0000111504.85822.b2

34. Ramakrishnan K. Evaluation and treatment of enuresis. Am Fam Physician. 2008;78(4):489-496.

35. Zhou J, Xia S, Li T, Liu R. Association between obstructive sleep apnea syndrome and nocturia: a meta-analysis. Sleep Breath. 2020;24 (4):1293-1298. doi:10.1007/s11325-019-01981-6

36. AbdelFatah D, Shaker H, Ismail M, Ezzat M. Nocturnal polyuria and nocturnal arginine vasopressin (AVP): a key factor in the pathophysiology of monosymptomatic nocturnal enuresis. Neurourol Urodyn. 2009;28(6):506-509. doi:10.1002/nau.20697

37. Birder LA, Van Kerrebroeck PEV. Pathophysiological mechanisms of nocturia and nocturnal polyuria: the contribution of cellular function, the urinary bladder urothelium, and circadian rhythm. Urology. 2019;133:14-23. doi:10.1016/j.urology.2019.07.020

38. Tsuji S, Takewa R, Ohnuma C, Kimata T, Yamanouchi S, Kaneko K. Nocturnal enuresis and poor sleep quality. Pediatr Int. 2018;60 (11):1020-1023. doi:10.1111/ped.13703

39. Kang BJ, Chung JM, Lee SD. Evaluation of functional bladder capacity in children with nocturnal enuresis according to type and treatment outcome. Res Rep Urol. 2020;12:383-389. doi:10.2147/ RRU.S267417

40. Lombardo R, Tubaro A, Burkhard F. Nocturia: the complex role of the heart, kidneys, and bladder. Eur Urol Focus. 2020;6(3):534-536. doi:10.1016/j.euf.2019.07.007

41. Link CL, Lutfey KE, Steers WD, McKinlay JB. Is abuse causally related to urologic symptoms? Results from the Boston area community health (BACH) survey. Eur Urol. 2007;52(2):397-406. doi:10.1016/j.eururo.2007.03.024

42. Vahabi B, Wagg AS, Rosier PF, et al. Can we define and characterize the aging lower urinary tract?-ICI-RS 2015. Neurourol Urodyn. 2017;36(4):854-858. doi:10.1002/nau.23035

43. Lloyd GL, Marks JM, Ricke WA. Benign prostatic hyperplasia and lower urinary tract symptoms: what is the role and significance of inflammation? Curr Urol Rep. 2019;20(9):54. doi:10.1007/s11934019-0917-1

44. Hartigan SM, Reynolds WS, Smith PP. Dilemmas in management of the geriatric bladder. Curr Bladder Dysfunct Rep. 2019;14 (4):272-279. doi:10.1007/s11884-019-00541-8

45. Camões J, Coelho A, Castro-Diaz D, Cruz F. Lower urinary tract symptoms and aging: the impact of chronic bladder ischemia on overactive bladder syndrome. Urol Int. 2015;95(4):373-379. doi:10.1159/000437336

46. Birder LA, Wolf-Johnston AS, Jackson EK, Wein AJ, Dmochowski R. Aging increases the expression of vasopressin receptors in both the kidney and urinary bladder. Neurourol Urodyn. 2019;38(1):393-397. doi:10.1002/nau.23830

47. Vickman RE, Franco OE, Moline DC, Vander Griend DJ, Thumbikat P, Hayward SW. The role of the androgen receptor in prostate development and benign prostatic hyperplasia: a review. Asian J Urol. 2020;7(3):191-202. doi:10.1016/j. ajur.2019.10.003

48. Siddiqui NY, Helfand BT, Andreev VP, et al. Biomarkers implicated in lower urinary tract symptoms: systematic review and pathway analyses. J Urol. 2019;202(5):880-889. doi:10.1097/JU.0000000 000000257 
49. Liguori I, Russo G, Curcio F, et al. Oxidative stress, aging, and diseases. Clin Interv Aging. 2018;13:757-772. doi:10.2147/CIA. $\mathrm{S} 158513$

50. Weiss JP, Blaivas JG. Nocturia. J Urol. 2000;163(1):5-12. doi:10.1016/S0022-5347(05)67961-X
51. Hascicek AM, Kilinc MF, Yildiz Y, Yuceturk CN, Doluoglu OG. A new checklist method enhances treatment compliance and response of behavioural therapy for primary monosymptomatic nocturnal enuresis: a prospective randomised controlled trial. World J Urol. 2019;37 (6):1181-1187. doi:10.1007/s00345-018-2478-1

\section{Publish your work in this journal}

Research and Reports in Urology is an international, peer-reviewed, open access journal publishing original research, reports, editorials, reviews and commentaries on all aspects of adult and pediatric urology in the clinic and laboratory including the following topics: Pathology, pathophysiology of urological disease; Investigation and

Submit your manuscript here: https://www.dovepress.com/research-and-reports-in-urology-journal treatment of urological disease; Pharmacology of drugs used for the treatment of urological disease. The manuscript management system is completely online and includes a very quick and fair peer-review system, which is all easy to use. Visit http://www.dovepress.com/ testimonials.php to read real quotes from published authors. 